\title{
Study of Electrical Properties of Polyaniline Films Prepared By Rf Plasma Polymerization
}

\author{
*P.Padwal ${ }^{1}$, S.V.Madhuskar ${ }^{2}$,S.Kulkarni ${ }^{3}$ \\ ${ }^{I}$ Shri Jagdishprasad Jhabarmal Tibrewala University,Jhunjhunu,Rajasthan,India. \\ ${ }^{2}$ S.S \& L.S Patkar-Varde College Goregaon(W) Mumbai. \\ ${ }^{3}$ The Institute of Science, Fort,Mumbai.
}

\begin{abstract}
Various methods like Chemical \& Electrochemical Polymerization are used for obtaining polyaniline thin films on metallic electrodes. But thin films prepared by Plasma Polymerization are chemically inert, of uniform thickness and thermally stable.It is because of these reasons the present work was done using Plasma Polymerization technique to prepare thin films of polyaniline on Aluminium substrate and its elctrical properties were investigated.The electrical conductivity of the film formed was measured and found to be in the order of $10^{-12} \mathrm{ohm}^{-1} \mathrm{~cm}^{-1}$. The electrical conductivity was considerably increased after doping the film by Iodine Vapours. The conductivity recorded after doping was of the order of $10^{-5} \mathrm{ohm}^{-1} \mathrm{~cm}^{-1}$. Thus by appropriate doping the conductivity of the Polyaniline film formed can be controlled and set to desired level.
\end{abstract}

Key words :Plasma Polymerization, Polyaniline films, Aluminium substrate, Electrical conductivity.

\section{I . Introduction}

Plasma Polymerisation is one of the widely used method for the formation Organic Film.Other methods include Chemical and Electrochemical Polymerizations.The films obtained by Plasma Polymerization are different from the films prepared by the conventional technique.Unlike films prepared by chemical and electrochemical methods, plasma polymerized films are pinhole-free, chemically inert, thermally stable and of uniform thickness[1]. It is because of these reasons that the current work was carried out using the Radio Frequency (RF) Glow Discharge Polymerization at an Operating Pressure of 0.1 Torr. Current work was carried out on plasma polymerized aniline because it exhibits electrical conductivity in the oxidized form. The electrical properties of the thin films formed on the Aluminium substrate were studied using a suitable technique. The Polyaniline thin films thus formed were then doped with Iodine with a view to increase its conductivity and the films thus formed were studied for its electrical properties and conductivities.

\section{Materials And Methods}

In the present study the deposition takes place on the substrate, which is exposed to plasmas. The current work was undertaken on Aluminium substrate. The substrate was ultrasonically cleaned and was kept in the chamber for Polymerization. The Polymerization was carried out at an operating pressure of 0.1 Torr using a rotary vane pump. The monomer (Aniline) was heated and the vapors along with the vapours of iodine were admitted into the chamber and the pressure was adjusted by controlling the flow of vapors using needle valves. The Experimental arrangement consists of a magnetron-enhanced plasma processing reactor. The schematic diagram of the setup is as shown. It consists of RF generator, Plasma reactor, Rotary vacuum pump and manifolds used to admit the Monomer along with the doping material into the chamber. The monomer (Aniline) was loaded into the sample holder and heated upto $150^{\circ} \mathrm{C}$ at a pressure of $0.1 \mathrm{Torr}$. Hence the monomer vapours along with doping monomer Iodine was admitted into the chamber and the polymerization was carried out at different polymerization duration times. The substrate used for the deposition were Aluminium plates which where ultrasonically cleaned and were kept in the chamber for plasma polymerization. 


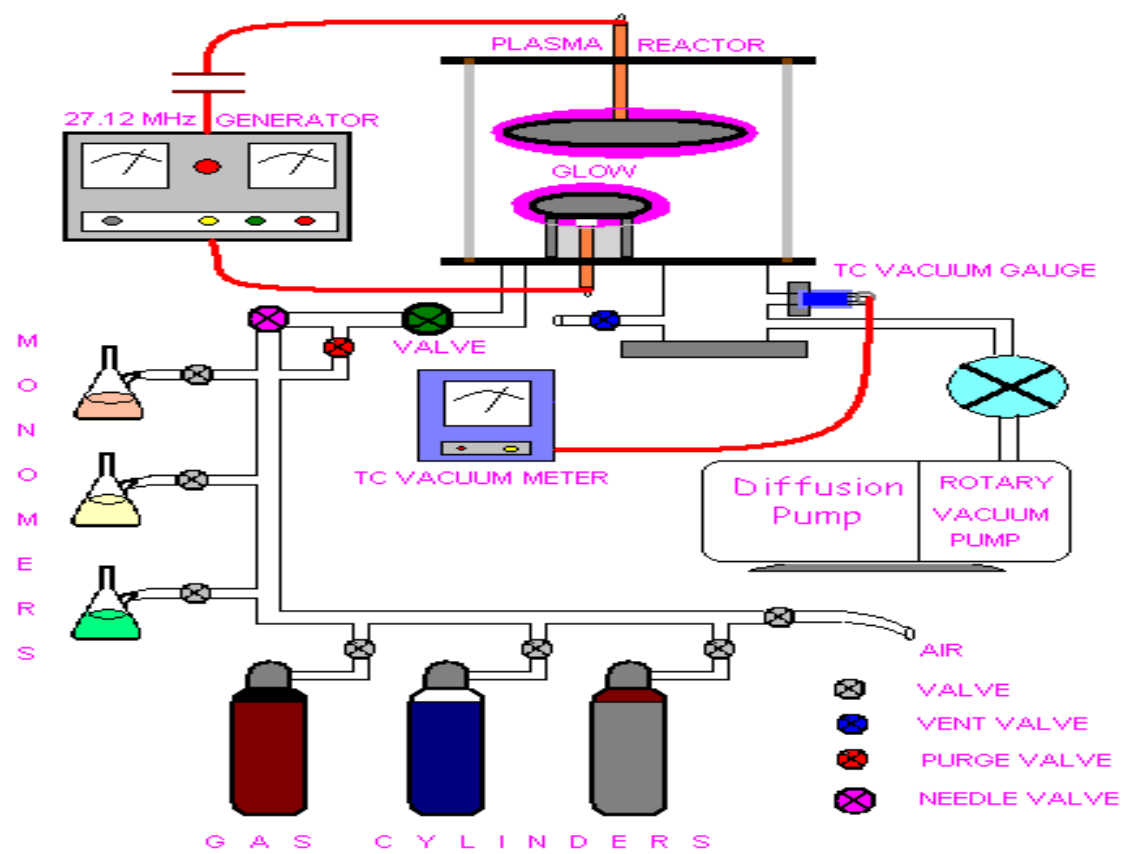

Fig.01 Magnetron-Enhanced Plasma Processing Reactor.

\section{Results And Discussions}

There are three conduction mechanisms, namely space charge limited conduction (SCLC), Schottky - type conduction and Poole - Frenkel conduction mechanism [2], and one of these can be dominant in a given sample.

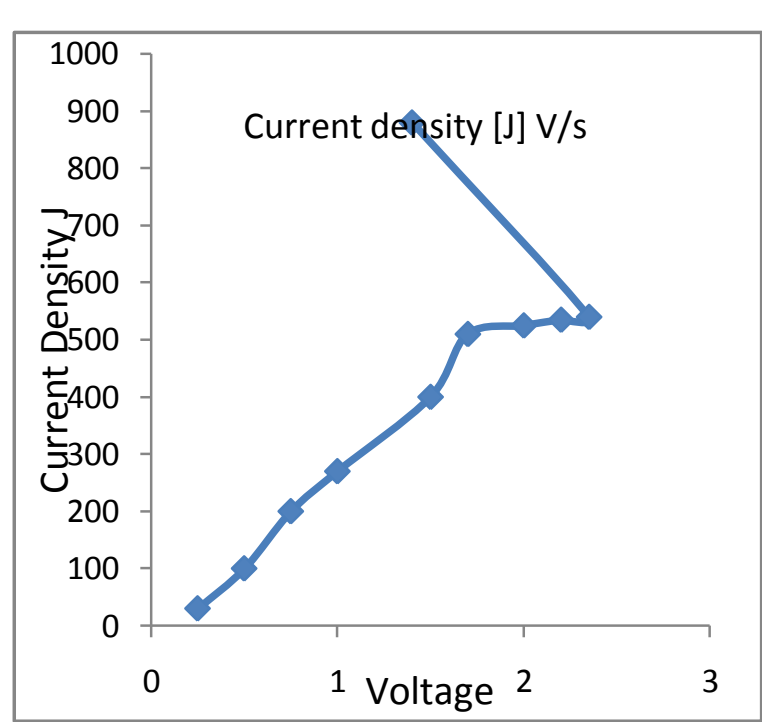

Fig.02

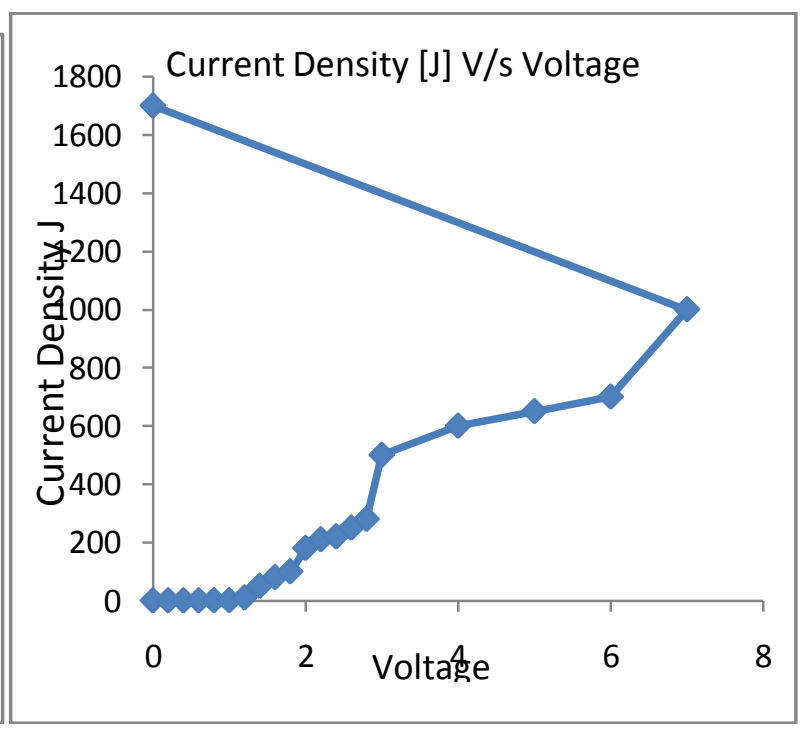

Fig.03

Figure 02 shows the plot of current density $\mathrm{J}$ ( $\mu \mathrm{A} / \mathrm{sqcm}$ ) versus sample voltage ( $\mathrm{V}$ ) for plasma polymerized $\mathrm{Al} /$ Polyaniline / $\mathrm{Cu}$ films having a thickness of $1500 \mathrm{~A}^{\circ}$. The polymerization was carried out for a period of 10 minutes on the Aluminium substrate. As can be observed from the plot after a certain voltage across the sample, breakdown of the sample takes place. The current study was carried out with a view to get recurring switching as reported earlier [3]. But instead of switching breakdown was observed, this may be due to the fact that the film thickness was considerably less as reported. 
Figure 03 shows a plot of current density $\mathrm{J}$ ( $\mu \mathrm{A} / \mathrm{sqcm}$ ) versus Voltage ( sample ) for plasma polymerized $\mathrm{Al} /$ Polyaniline / $\mathrm{Cu}$ films which were prepared for a polymerization time duration of 15 minutes and having a thickness of $2500 \mathrm{~A}^{\circ}$. As observed from figure 2 the breakdown voltage of the sample increases as the polymerization time is increased.

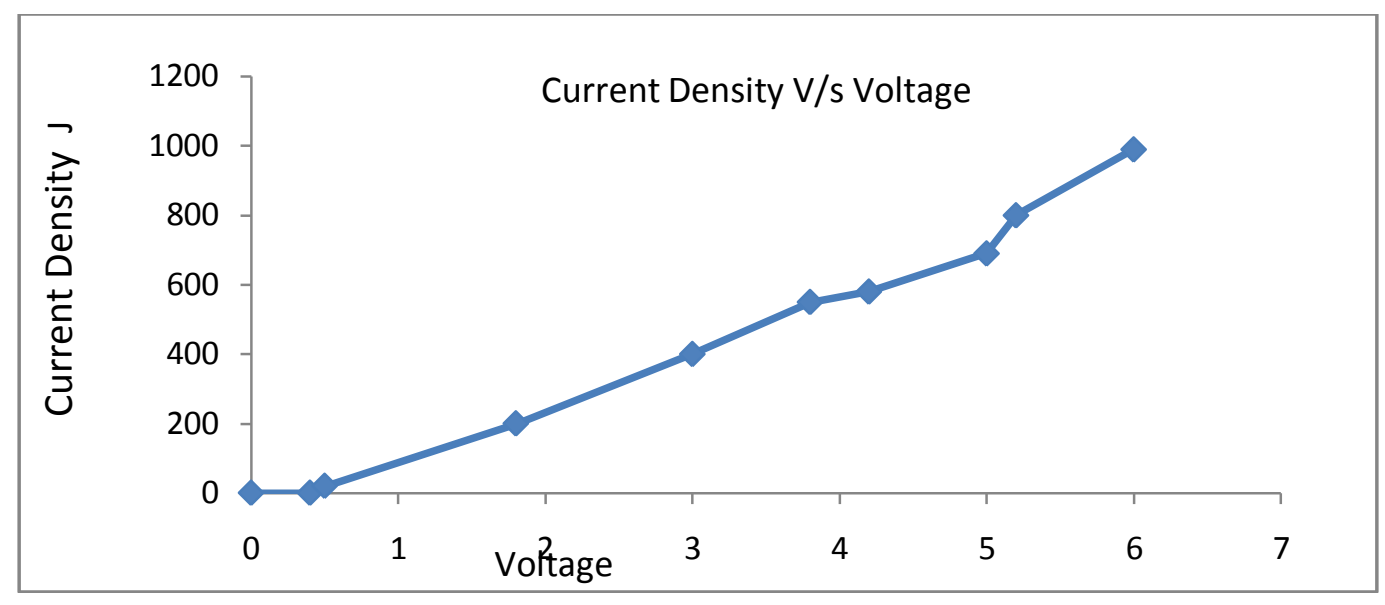

Fig.04

Figure 04 shows the plot of current density $\mathrm{J}(\mu \mathrm{A} / \mathrm{sqcm})$ versus applied voltage for a plasma polymerized thin film of $\mathrm{Al} /$ polyaniline / $\mathrm{Cu}$ prepared on Aluminium substrate for a time period of 10 minutes. The graph shows that for lower values of applied voltage it is a straight line for which the slope is one and further as applied voltage increases the graph becomes non linear.

\section{Conclusion}

The Plasma polymerized polyaniline films show a variation in the breakdown voltage as the polymerization time is increased.

\section{Acknowledgement}

Authors wish to thank Dr.S.V. Maduskar \& Dr.S.Kulkarni for their constant encouragement and suggestions. Authors wish to thank Patkar College and Institute of Science for providing financial support.

\section{References}

[1] N.P. Chermisinoff, Handbook of Polymer Science and Technology, vol. 4, Marcel Dekker, New York, ( 1989. )

[2] D.R. Lamb, Electrical Conduction Mechanisms in Thin Insulating Films, Methuen, London, ( 1967 ).

[3] Maciej Gazicki and H. Yasuda, Plasma Chemistry and Plasma Processing, vol 3, No.3, ( 1983 ). 